\title{
Dual-Energy CTA in Patients with Symptomatic Peripheral Arterial Occlusive Disease: Study of Diagnostic Accuracy and Impeding Factors
}

\section{Dual Energy CTA bei Patienten mit symptomatischer PAVK: Studie über die diagnostische Genauigkeit und limitierende Faktoren}

Authors

Thorsten Klink ${ }^{1,3}$, Theresa Wilhelm², Christine Roth², Johannes T. Heverhagen ${ }^{3}$

Affiliations

1 Institute of Diagnostic and Interventional Radiology, University of Würzburg, Germany

2 Department of Diagnostic and Interventional Radiology, University Hospital Giessen and Marburg, Campus Marburg, Germany

3 University Institute of Diagnostic, Interventional, and Pediatric Radiology, Inselspital - University Hospital, University of Bern, Bern, Switzerland

Key words

vascular, CT angiography, dual-energy computed tomography angiography, peripheral artery occlusive disease, critical limb ischemia

received 25.8.2016

accepted 4.1 .2017

Bibliography

DOI http://dx.doi.org/10.1055/s-0043-101526

Published online: 1.3.2017 | Fortschr Röntgenstr 2017; 189:

441-452

(c) Georg Thieme Verlag KG Stuttgart · New York ISSN 1438-9029

Correspondence

Priv.-Doz. Dr. Thorsten Klink, EBCR

Insitute of Diagnostic and Interventional Radiology,

University of Würzburg

Oberdürrbacherstraße 6

97080 Würzburg

Germany

Tel.: ++49/931/20134959

Fax: ++49/931/201634001

Klink_T1@ukw.de

\section{ZUSAMMENFASSUNG}

Zielsetzung Das Ziel dieser Studie war, die diagnostische Genauigkeit der Dual-energy CT Angiographie (DE-CTA) bei Patienten mit symptomatischer peripherer arterieller Verschluss- krankheit (pAVK) zu erfassen, und Faktoren zu identifizieren, die die diagnostische Genauigkeit negativ beeinflussen.

Material und Methoden Dual-source DE-CTA Untersuchungen der unteren Extremitäten von 94 Patienten wurden retrospektiv mit dem diagnostischen Referenzstandard digitale Subtraktionsangiografie (DSA) verglichen. Zwei unabhängige Auswerter haben die Inzidenz der PAVK, die Bildqualität, Artefakte und die diagnostische Genauigkeit der DE-CTA in 1014 arteriellen Segmenten anhand axialer, kombinierter 80/ $140 \mathrm{kVp}$ Rekonstruktionen und 3 D Maximum-Intensitäts-Projektionen (MIP) nach automatischer Knochen- und Plaqueentfernung ausgewertet. Der Einfluss von Verkalkungen, der Bildqualität und von -artefakten auf die diagnostische Genauigkeit wurde mittels Fisher Tests evaluiert. Darüber hinaus wurde die Übereinstimmung der Auswerter analysiert. Ergebnisse Die zwei Auswerter erzielten Sensitivitätswerte von $98,0 \%$ und $93,9 \%$, und Spezifitätswerte von $75,0 \%$ und $66,7 \%$ bei der Detektion von Stenosen $>50 \%$. Verkalkungen beeinflussten die Spezifität negativ, z. B. von $81,2 \%$ auf $46,2 \%$ bei Auswerter $1(p<0,001)$. Die Spezifität nahm bei besserer Bildqualität signifikant zu, z. B. von $70,0 \%$ auf $76,4 \%$ bei Auswerter $1(p<0,001)$. Artefakte reduzierten die Spezifität von Auswerter 2 signifikant $(p<0,001)$. Die Übereinstimmung der Auswerter war moderat bis substanziell bei der Stenosedetektion und Kalkplaqueauswertung.

Schlussfolgerungen Die DE-CTA ermöglicht eine zuverlässige Detektion von > 50 \%igen Stenosen bei Patienten mit symptomatischer pAVK. Kalzifizierte atherosklerotischen Plaques, die Bildqualität, -artefakte können die Spezifität negative beeinflussen.

\section{Kernaussagen:}

- Die Sensitivitätswerte (DE-CTA) waren 98,0 und 93.9\%, die Spezifitätswerte $75,0 \%$ und $66,7 \%$.

- Die Auswerterübereinstimmg war moderat bis substanziell für die Stenose- und Plaquedetektion.

- Kalkplaques, Bildqualität und Artefakte können die Spezifität beeinträchtigen.

\section{ABSTRACT}

Purpose The purpose of this study was to assess the diagnostic performance of dual-energy CT angiography (DE-CTA) in patients with symptomatic peripheral artery occlusive disease (PAOD) and to identify factors that impede its diagnostic accuracy. 
Materials and Methods Dual-source DE-CTA scans of the lower extremities of 94 patients were retrospectively compared to the diagnostic reference standard, digital subtraction angiography (DSA). Two independent observers assessed PAOD incidence, image quality, artifacts, and diagnostic accuracy of DECTA in 1014 arterial segments on axial, combined 80/140 kVp reconstructions and on $3 \mathrm{D}$ maximum intensity projections (MIP) after automated bone and plaque removal. The impact of calcifications, image quality, and image artifacts on the diagnostic accuracy was evaluated using Fisher's exact test. Furthermore, interobserver agreement was analyzed.

Results Two observers achieved sensitivities of $98.0 \%$ and $93.9 \%$, respectively, and specificities of $75.0 \%$ and $66.7 \%$, respectively, for detecting stenoses of $>50 \%$ of the lower extremity arteries. Calcifications impeded specificity, e. g. from $81.2 \%$ to $46.2 \%$ for reader 1 ( $p<0.001)$. Specificity increased with higher image quality, e. g. from $70.0 \%$ to $76.4 \%$ for reader 1 $(p<0.001)$. Artifacts decreased the specificity of reader 2 $(p<0.001)$. The overall interobserver agreement ranged be- tween moderate and substantial for stenosis detection and calcified plaques.

Conclusion DE-CTA is accurate in the detection of arterial stenoses of $>50 \%$ in symptomatic PAOD patients. Calcified atherosclerotic plaques, image quality, and artifacts may impede specificity.

\section{Key Points:}

- Sensitivities of DE-CTA were 98.0 and $93.9 \%$, specificities $75.0 \%$ and $66.7 \%$.

- Interobserver agreement was moderate to substantial for stenosis and plaque detection.

- Calcified atherosclerotic plaques, image quality, and artifacts may impede specificity.

\section{Citation Format}

- Klink T, Wilhelm T, Roth C et al. Dual-Energy CTA in Patients with Symptomatic Peripheral Arterial Occlusive Disease: Study of Diagnostic Accuracy and Impeding Factors. Fortschr Röntgenstr 2017; 189: 441-452

\section{Introduction}

Digital subtraction angiography (DSA) is the traditional reference standard for diagnosing peripheral artery occlusive disease (PAOD) of the lower extremities. DSA is not only an excellent diagnostic tool for PAOD but is also a key for interventional treatment of relevant artery stenoses under current therapy guidelines $[1,2]$. Nevertheless, DSA is an invasive procedure with potential complications [3] and so less invasive and more comfortable angiography techniques are desired when imaging is primarily performed for diagnostic purposes or for therapy planning [4].

The status of lower extremity arteries in patients with suspected PAOD can be accurately assessed with noninvasive computed tomography angiography (CTA). In two systematic reviews with meta-analyses, single-source, single-energy multi-slice CT scanners (16- and 64-MSCT) rendered sensitivities of $92 \%$ and $95 \%$, respectively, and specificities of $93 \%$ and $96 \%$, respectively, for detecting arterial stenoses of more than $50 \%[5,6]$.

However, atherosclerotic calcifications may impede the assessment of arterial segments on standard CTA images [7]. In small caliber arteries, calcified plaques may not be distinguishable from luminal contrast enhancement impairing reliable stenosis grading and increasing interobserver variability. CTA acquisitions in dualenergy technique (DE-CTA) are considered helpful for ameliorating the drawback of limited tissue differentiation. DE-CTA scans allow for better differentiation of contrast material, atherosclerotic plaques, and osseous structures utilizing accentuated maximum density differences between $80 \mathrm{kV}$ and $140 \mathrm{kV}$ [8]. DE-CTA image postprocessing includes automated bone and atherosclerotic plaque removal. Creation of multi-planar reconstructions or luminographic maximum intensity projections (MIP) has thus proven to be less time-consuming than standard CTA scans [11] and provides better visualization and characterization of vascular findings. Furthermore, DE-CTA may be performed with lower contrast material doses in patients with reduced kidney function due to the higher pho- toelectric effect at lower tube voltages. DE-CTA scans do not necessarily lead to increased radiation exposure in comparison to standard CTA scans, but may potentially reduce radiation, e. g. by calculating virtual native images instead of additional non-contrast scans when endoleaks are sought [9].

The aim of this study was to assess the diagnostic accuracy of DE-CTA in comparison to the diagnostic reference standard DSA. Because several existing studies have produced promising and convincing results for DE-CTA in PAOD patients with rather mild or mixed severity, we focused on patients with critical limb ischemia or severe symptoms of PAOD. In addition, we assessed the influence of atherosclerotic calcifications, image quality, and the presence and types of artifacts on the diagnostic accuracy of DE-CTA, which still are not sufficiently valued and studied aspects for potential image limitations. Furthermore, we evaluated the interobserver agreement of the DE-CTA readers.

\section{Materials and methods}

\section{Subjects}

The local ethics committee approved this retrospective diagnostic study (petition no. 80/09). Patients who were referred for runoff DE-CTA of the pelvis and the lower limbs due to clinical symptoms of peripheral arterial occlusive disease (PAD) between 01/2008 and 09/2009 were retrospectively selected for this study. The patients were included in the study if they had an additional digital subtraction angiography of the same body region within 30 days after the DE-CTA scan. - Fig. 1 shows the patient selection process in a flow chart.

In all, 99 DE-CTA studies of 94 consecutive patients (mean age: 72.7 years; age range: 40 - 96; female: 32 ; male: 62 ) with subsequent DSA could be included in the study, resulting in 198 extremities for evaluation. In 5 patients, DE-CTA and DSA scans were repeated during the study period due to recurrent symptoms of PAOD. The degree 


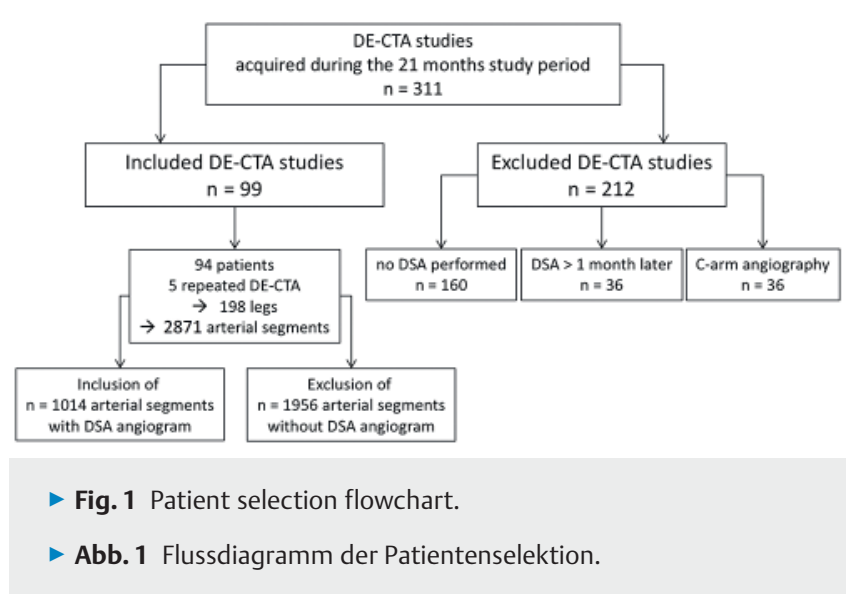

of PAOD, classified according to clinical symptoms as described by Fontaine [10], was documented in 123 of the 198 cases. None of the cases were stage I, 1 case was stage Ila, 16 cases were stage IIb, 27 cases were stage III, and 79 cases were stage IV.

\section{Dual-energy CT angiography}

Runoff DE-CTA was performed using a first-generation 64-slice dual-source CT scanner (Somatom Definition; Siemens Healthcare, Forchheim, Germany) applying the following parameters: tube voltages: 140 and $80 \mathrm{kV}$; effective tube current: 50 (140kVp) and $270 \mathrm{mAs}(80 \mathrm{kVp})$; collimation: $64 \times 1.2 \mathrm{~mm}$; gantry rotation time: $0.5 \mathrm{~s}$; table movement: $40 \mathrm{~mm} / \mathrm{s}$; and pitch factor: 1.0. Patients were scanned feet-first in supine position. Pre-warmed contrast material (Ultravist 370, Bayer Schering Pharma, Leverkusen, Germany) was automatically injected via an antecubital 18-gauge vein catheter at a flow rate of $4.0 \mathrm{ml} / \mathrm{s}$. CT acquisition was initiated using the Care Bolus technique when the mean density within an region-of-interest (ROI) reached the level of 150 Houndsfield Units (HU) during contrast material injection of $80 \mathrm{ml}$ with a delay of $5 \mathrm{~s}$. The runoff scan covered the volume between the infrarenal aorta and the toes.

\section{CT image post-processing}

CT images were reconstructed in axial orientation with a slice thickness of $1.5 \mathrm{~mm}$ and an increment of $1.0 \mathrm{~mm}$ using filtered back-projection and a medium vessel kernel. Axial reconstructions were further post-processed using the dual-energy application (VE25A, Siemens Healthcare, Germany). The dual-energy software application removed bone and rendered the automated removal of calcified plaques due to spectral differences from luminal iodine enhancement ( $\bullet$ Fig. 2). Specific absorption characteristics at 80 and $140 \mathrm{kVp}$ allow for differentiation of calcified structures and iodine. First, axial images were automatically combined to $80 \mathrm{kVp} / 140 \mathrm{kVp}$ images with weighting of $60 \% / 40 \%$. Axial MPRs with these settings were generated and used for evaluation. Secondly, three-dimensional maximum intensity projections (MIPs) after automatic bone and plaque removal were generated with a $180^{\circ}$ circumference in $10^{\circ}$ increments. These MIPs were part of the image assessment. Both axial MPRs and $3 \mathrm{D}$ MIPs had been sent to the PACS and were evaluated by two CTA readers.

\section{Digital subtraction angiography}

Digital subtraction angiography (DSA) was considered the diagnostic gold standard. The mean time interval between DSA acquisition and the DE-CTA scan was 7.1 days (range: 0 - 29 days). Images were acquired using the DSA unit "Artis Zee Heeling" combined with Syngo imaging software (Siemens Healthcare, Erlangen, Germany). DSA was performed for interventional or surgical therapy planning.

The femoral artery of the non-/less-symptomatic lower limb was accessed in retrograde direction after local anesthesia (mepiracain; Scandicain, Astra Zeneca, Wedel, Germany) using an 18-gauge puncture needle, when pelvic segment stenosis could not be excluded. A $5 \mathrm{~F}$ pigtail catheter was introduced via a $5 \mathrm{~F}$ introducer sheath (Avanti Plus, Cordis Corp., Bridgewater, NJ) over guidewire and placed in the infrarenal abdominal aorta. In other cases, lower extremity arteries were accessed via an antegrade puncture of the common femoral artery of the diseased extremity. Contrast material (Ultravist 300, Bayer Schering Pharma, Leverkusen, Germany) was either automatically injected using the angiographic injection system (Mark V ProVis, Medrad Europe, Netherlands) at a flow rate of $15 \mathrm{ml} / \mathrm{s}$ for the pelvis region $(30 \mathrm{ml})$, or manually for peripheral projections $(10 \mathrm{ml})$. At the pelvis level, images were acquired in posterior-anterior (PA), and oblique $\left(30^{\circ}\right)$ PA views with a frame rate of 2 images per second. The proximal thigh was imaged in PA and oblique PA views with 1 frame per second. The lower leg and feet were imaged in PA/oblique PA/parallel to the plane of the interosseous membrane with a frame rate of 1 per second.

\section{Image assessment}

Two radiologists with 12 and 8 years of experience in diagnostic vascular imaging reviewed DE-CTA images. Both readers assessed images independently and were blinded to all clinical information and radiological imaging and reporting. A third independent reader, an interventional radiologist with 11 years of experience, reviewed all DSA images. This reader was blinded to DE-CTA images, but had access to clinical and therapy information. The findings documented by this reader were considered the diagnostic reference standard. All readers evaluated images on a PACS workstation (IMPAX, Agfa HealthCare, Germany).

\section{Criteria for segmental assessment of arteries}

The aorta and the arteries of the pelvis and the lower extremities were subdivided into 15 segments: Infrarenal abdominal aorta (IAA), common iliac artery (CIA), internal iliac artery (IIA), external iliac artery (EIA), common femoral artery (CFA), femoral artery bifurcation (FAB), superficial femoral artery (SFA), profound femoral artery (PFA), popliteal artery (PA), anterior tibial artery (ATA), tibial-fibular trunk (TFT), posterior tibial artery (PTA), fibular artery (FA), dorsal pedal artery (DPA), and plantar pedal artery (PPA). The arterial segments were grouped into the following vessel regions: Pelvis (CIA, IIA, EIA), above knee (CFA, FAB, SFA, PFA, PA), below knee (ATA, TFT, PTA, FA), and foot (DPA, PPA). 

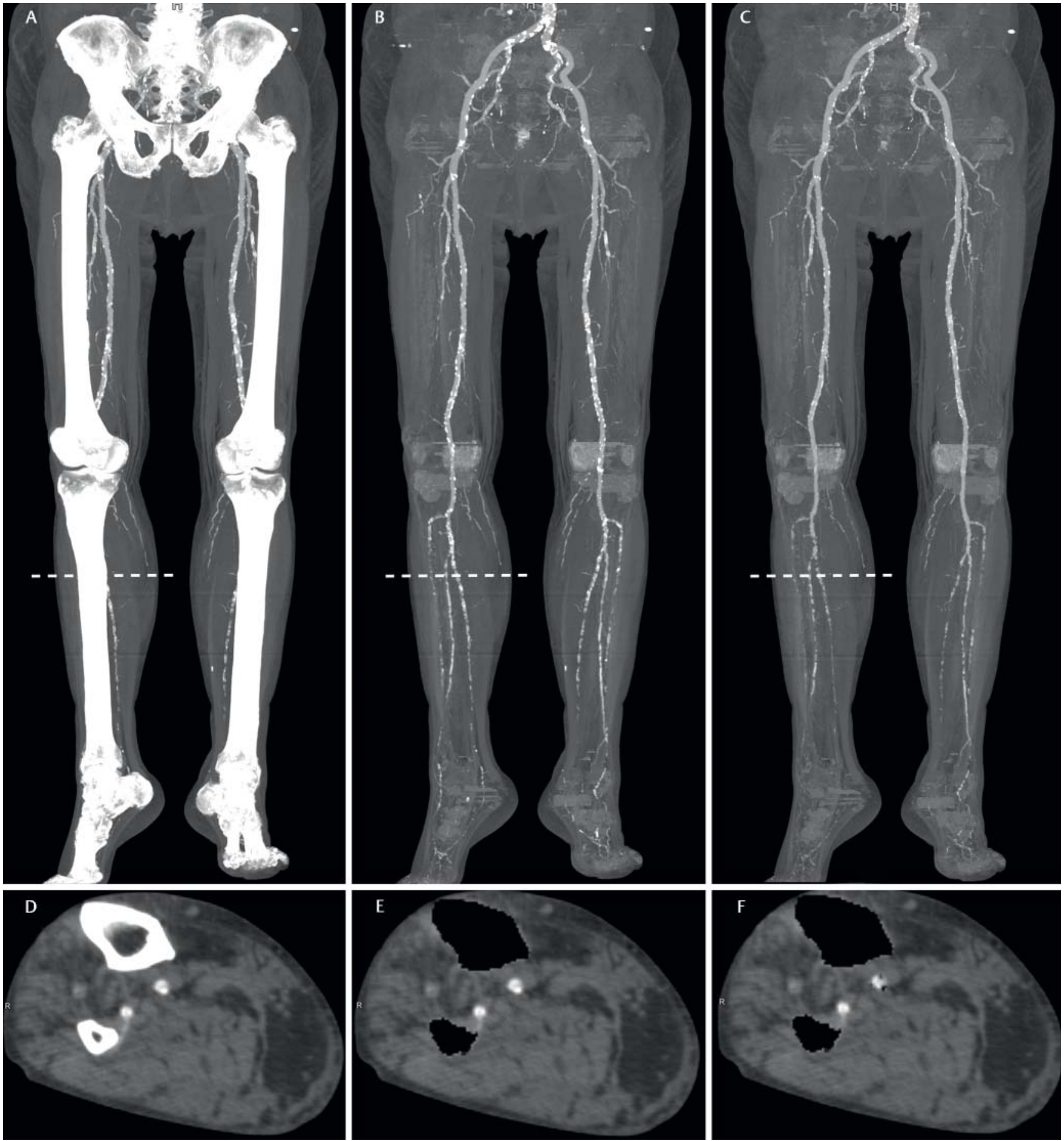

- Fig. 2 The software automatically renders the subtraction of bones and plaques from non-processed 80/140 kVp dual-energy images. Coronal MIPs and axial MPR images at the level of the proximal lower leg demonstrate the post-processing from non-processed images $\mathbf{A}, \mathbf{B}$ to images after bone removal $\mathbf{C}$, D and after bone and plaque removal E, F. The cross-sections reveal occlusion of the proximal ATA and contrast-enhanced lumens of PTA and FA.

- Abb. 2 Die Software vollführt eine automatische Subtraktion der knöchernen Strukturen und der Kalkplaque von den nicht-verarbeiteten 80 / 140 kVp Dual-energy Bildern. Koronare MIPs und axiale MPR Bilder auf Höhe des proximalen Unterschenkels zeigen die Nachverarbeitung von den nicht-verarbeiteten Bildern A, B, über die Bilder nach Entfernung der knöchernen Strukturen C, D und nach zusätzlicher Plaqueentfernung E, F. Die Querschnittsbilder zeigen einen Verschluss der proximalen A. tibialis anterior und eine Kontrastierung der A. tibialis posterior und fibularis.

The DSA reader and the two DE-CTA readers and the DSA reader reviewed and evaluated each arterial segment of all patients according to the following evaluation criteria:
1. The degree of stenosis was subjectively determined by estimating the percentage of lumen reduction in relation to the proximally adjacent non-stenotic lumen. Stenoses were cate- 
gorized as no stenosis, stenosis of less than $50 \%$, stenosis of $51 \%$ to $70 \%$, stenosis of $71 \%$ to $99 \%$, and occlusion.

2. Calcifications were categorized as no calcifications, minor calcifications that involved less than $1 / 3$ of the lumen circumference, moderate calcifications that involved between $1 / 3$ and $2 /$ 3 of the lumen circumference, and severe calcifications that involved more than 2/3 of the lumen circumference.

3. Image quality was subjectively evaluated taking the depiction of anatomical structures, image contrast and resolution, and limitations due to artifacts into account. Image quality was categorized into not adequate, acceptable, good, and excellent. Image quality was assessed per vascular region.

4. Image artifacts were categorized as no artifacts, artifacts without limitation of image interpretation, and artifacts with limitation of image interpretation.

5. The following types of artifacts were documented: suboptimal vessel enhancement, motion artifacts, venous contamination, beam-hardening artifacts, and other artifacts (e. g. stent artifacts).

\section{Processing and analyses of findings and results}

All findings and results of both CTA readers were separately compared to the results of the DSA reader.

\section{Incidence analyses}

Incidences of arterial stenosis and atherosclerotic calcifications were documented for each arterial segment. Arterial stenoses of $>50 \%$ were considered a positive finding. Furthermore, image quality as well as the presence and type of imaging artifacts were documented. Results were summarized in contingency tables and presented per segment or grouped per extremity or arterial region. Extremities or regions were considered "stenosis-positive" if at least one arterial segment had a positive finding. When arterial segments were not assessable because they were not included in the scanned volume, e.g. due to prior amputation, segments were rejected. When arterial segments were not assessable due to limited image quality, e. g. beam hardening artifacts due to metal implants, segments were also rejected. All calculations were performed per leg, per region, and per arterial segment.

\section{Statistical analyses}

\section{Diagnostic performance}

The diagnostic performance of DE-CTA for the detection of arterial stenoses of $>50 \%$ was assessed in comparison to the diagnostic reference standard DSA. Sensitivity, specificity, and likelihood ratios were calculated for each reader. These calculations required matching of the arterial segments displayed on DE-CTA and DSA images. When arterial segments could not be matched, for example if they were not visualized, they were rejected from analysis.

Impact of calcifications, image quality, and image artifacts on the diagnostic performance of DE-CTA

Fisher's exact test was performed to test whether atherosclerotic calcifications, image quality, the presence of artifacts, and the type of artifact had a significant influence on the diagnostic accuracy of DE-CTA.

\section{Interobserver agreement and further statistical analyses}

Interobserver agreement was assessed using Kappa statistics [11]. Interobserver agreement was considered almost perfect for $\mathrm{K}=0.81-1.0$, substantial for $\mathrm{K}=0.61-0.8$, moderate for $\mathrm{K}=0.41-0.6$, fair for $\mathrm{K}=0.21-0.4$, and slight for $\mathrm{K}=0-0.2$. Calculations and further statistical analyses were performed using the SPSS (Version 21.0, IBM, USA) and Prism (Version 6.0c, GraphPad Software, USA). P-values of $<0.05$ were considered statistically significant. When results for both observers are given, the first is the result of reader 1 , and the second the result of reader 2 .

\section{Results}

\section{Incidence analysis}

\section{Degree of stenosis}

- Table 1 illustrates the frequency distribution for the degree of stenosis detected on DE-CTA by each observer in comparison to DSA for all evaluable 1014 artery segments. DE-CTA led to fewer stenosis exclusions than DSA, while occlusions were found in a comparable number of arterial segments. The interobserver evaluation of both readers for detecting stenoses of $>50 \%$ resulted in strong agreement for all arteries $(\kappa=0.623)$. The agreement was substantial in the pelvis region $(\mathrm{K}=0.556)$, strong in the thigh region ( $\mathrm{K}=0.639$ ), substantial in the lower leg region $(\kappa=0.565)$, and fair in the foot region $(\kappa=0.362)$.

\section{Degree of calcification}

- Table 2 shows the severity distribution for segmental artery calcifications detected on DE-CTA by each observer in comparison to DSA for all evaluable 1014 artery segments. The readers detected more calcifications and a greater extent of calcification using DE-CTA in comparison to DSA. The interobserver agreement of both readers was substantial $(\kappa=0.518)$. The regional interobserver agreement was substantial in the pelvis region $(\mathrm{K}=0.457)$, substantial in the thigh region $(\mathrm{K}=0.451)$, and fair in the lower leg and foot region $(\kappa=0.359)$.

\section{Image quality}

- Table 3 demonstrates the frequency distribution of image quality of DE-CTA in comparison to DSA for all evaluable 252 regions. The interobserver agreement of both readers was poor $(\mathrm{k}=0.017)$. Reader 1 considered the quality of 160 regions excellent, 77 regions good, 11 regions acceptable, and 4 not adequate. Reader 2 considered the quality of 24 regions excellent, 183 good, 39 acceptable, and 6 not adequate. Table 4 demonstrates the frequency distribution for the presence and degree of imaging artifacts detected on DE-CTA by each observer in comparison to DSA for all evaluable $1014 \mathrm{seg}$ ments. The interobserver agreement of both readers was fair $(\mathrm{K}=0.225)$. The categorization of artifacts is given in $>$ Table 5. The most common artifact of DE-CTA was venous contrast material contamination at the acquisition time point found in $5.8 \%$ of arterial segments. The interobserver agreement of both readers was fair $(\mathrm{K}=0.257)$. 
- Table 1 Stenosis degree of artery segments. Incidence comparison of DE-CTA versus DSA. The table show the results of the first reader only. The second reader had similar results. Kappa values for the determination of the interobserver agreement are given in the text.

- Tab. 1 Stenosegraduierung in den arteriellen Segmenten. Vergleich der Inzidenzen bei der DE-CTA und der DSA. Die Tabelle zeigen nur die des ersten Auswerters, der zweite Auswerter erzielte vergleichbare Ergebnisse. Die Kappa Werte zur Einschätzung der Auswerterübereinstimmung sind im Text genannt.

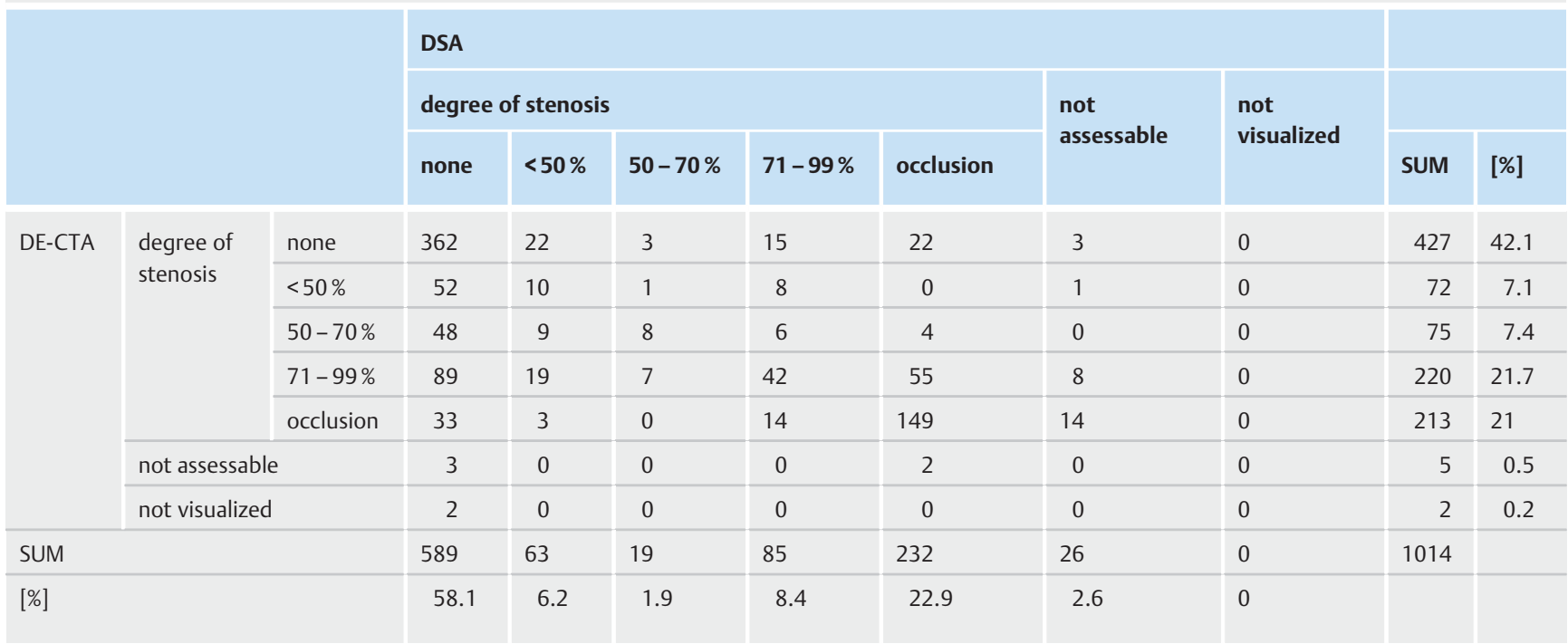

- Table 2 Degree of calcification. Incidence comparison of DE-CTA versus DSA. The table show the results of the first reader only. The second reader had similar results. Kappa values for the determination of the interobserver agreement are given in the text.

- Tab.2 Verkalkungsgrad. Vergleich der Inzidenzen bei der DE-CTA und der DSA. Die Tabelle zeigen nur die des ersten Auswerters, der zweite Auswerter erzielte vergleichbare Ergebnisse. Die Kappa Werte zur Einschätzung der Auswerterübereinstimmung sind im Text genannt.

\begin{tabular}{|c|c|c|c|c|c|c|c|c|c|c|}
\hline & & & \multicolumn{6}{|l|}{ DSA } & & \multirow[b]{3}{*}{ [\%] } \\
\hline & & & \multicolumn{4}{|c|}{ degree of calcification } & \multirow{2}{*}{$\begin{array}{l}\text { not } \\
\text { assessable }\end{array}$} & \multirow{2}{*}{$\begin{array}{l}\text { not } \\
\text { visualized }\end{array}$} & \multirow[b]{2}{*}{ SUM } & \\
\hline & & & none & $<1 / 3$ & $1 / 3-2 / 3$ & $>2 / 3$ & & & & \\
\hline \multirow[t]{6}{*}{ DE-CTA } & \multirow{4}{*}{$\begin{array}{l}\text { degree of } \\
\text { calcification }\end{array}$} & none & 322 & 39 & 5 & 1 & 4 & 0 & 371 & 36.6 \\
\hline & & $<1 / 3$ & 145 & 18 & 5 & 1 & 3 & 0 & 172 & 17.0 \\
\hline & & $1 / 3-2 / 3$ & 47 & 10 & 0 & 0 & 0 & 0 & 57 & 5.6 \\
\hline & & $>2 / 3$ & 243 & 84 & 43 & 16 & 21 & 0 & 407 & 40.1 \\
\hline & \multicolumn{2}{|c|}{ not assessable } & 2 & 1 & 2 & 0 & 0 & 0 & 5 & 0.5 \\
\hline & \multicolumn{2}{|l|}{ not visualized } & 2 & 0 & 0 & 0 & 0 & 0 & 2 & 0.2 \\
\hline \multicolumn{3}{|l|}{ SUM } & 761 & 152 & 55 & 18 & 28 & 0 & 1014 & \\
\hline \multicolumn{3}{|l|}{ [\%] } & 75.0 & 15.0 & 5.4 & 1.8 & 2.8 & 0.0 & & \\
\hline
\end{tabular}

\section{Diagnostic accuracy}

The sensitivity of DE-CTA for the detection of stenosis of any degree was $85.3 \%$ and the specificity was $68.9 \%$ in comparison to DSA for observer 1 , and $74.4 \%$ and $77.0 \%$ for observer 2 . The diagnostic accuracy was $74.5 \%$ for observer 1 and $77.0 \%$ for observer 2. - Table 6 demonstrates that the diagnostic accuracy of DE-CTA increases when the test was considered positive for true-positive stenosis of $>50 \%$ in at least one arterial segment per extremity, and negative for stenoses of $<50 \%$. Here, the two observers produced a mean sensitivity of $96 \%$ and a mean specificity of $71 \%$. The diagnostic accuracy evaluation of arterial regions given as means of both observers resulted in a sensitivity of $73 \%$ and a specificity of $70 \%$ at the pelvis level, a sensitivity of $90 \%$ and a specificity of $79 \%$ at the thigh level, a sensitivity of $86 \%$ and a specificity of $49 \%$ at the lower leg level, and a sensitivity of $77 \%$ and a specificity of $54 \%$ at the pedal level. D Table 7 shows the diagnostic accuracy of DE-CTA for each arterial segment. The diagnostic accuracy decreased from proximal to distal with the exception of the internal iliac artery (IIA), 
- Table 3 Image quality. Incidence comparison of DE-CTA versus DSA. The table show the results of the first reader only. The second reader had similar results. Kappa values for the determination of the interobserver agreement are given in the text.

- Tab.3 Bildqualität. Vergleich der Inzidenzen bei der DE-CTA und der DSA. Die Tabelle zeigen nur die des ersten Auswerters, der zweite Auswerter erzielte vergleichbare Ergebnisse. Die Kappa Werte zur Einschätzung der Auswerterübereinstimmung sind im Text genannt.

\begin{tabular}{|c|c|c|c|c|c|c|c|}
\hline & & \multicolumn{4}{|l|}{ DSA } & \multirow[b]{2}{*}{ SUM } & \multirow[b]{2}{*}{ [\%] } \\
\hline & & not adequate & acceptable & good & excellent & & \\
\hline \multirow[t]{4}{*}{ DE-CTA } & not adequate & 0 & 0 & 0 & 4 & 4 & 1.6 \\
\hline & acceptable & 0 & 0 & 0 & 11 & 11 & 4.4 \\
\hline & good & 3 & 1 & 2 & 71 & 77 & 30.6 \\
\hline & excellent & 0 & 0 & 3 & 157 & 160 & 63.5 \\
\hline \multicolumn{2}{|l|}{ SUM } & 3 & 1 & 5 & 243 & 252 & \\
\hline \multicolumn{2}{|l|}{ [\%] } & 1.2 & 0.4 & 2.0 & 96.4 & & \\
\hline
\end{tabular}

- Table 4 Presence of image artifacts. Incidence comparison of DE-CTA versus DSA. The table show the results of the first reader only. The second reader had similar results. Kappa values for the determination of the interobserver agreement are given in the text.

- Tab.4 Präsenz von Bildartefakten. Vergleich der Inzidenzen bei der DE-CTA und der DSA. Die Tabelle zeigen nur die des ersten Auswerters, der zweite Auswerter erzielte vergleichbare Ergebnisse. Die Kappa Werte zur Einschätzung der Auswerterübereinstimmung sind im Text genannt.

\begin{tabular}{|c|c|c|c|c|c|c|c|c|c|}
\hline & & & \multicolumn{5}{|l|}{ DSA } & \multirow[b]{3}{*}{ SUM } & \multirow[b]{3}{*}{ [\%] } \\
\hline & & & \multicolumn{3}{|c|}{ artifacts } & \multirow{2}{*}{$\begin{array}{l}\text { not } \\
\text { assessable }\end{array}$} & \multirow{2}{*}{$\begin{array}{l}\text { not } \\
\text { visualized }\end{array}$} & & \\
\hline & & & none & $\begin{array}{l}\text { present with- } \\
\text { out limitation }\end{array}$ & $\begin{array}{l}\text { present with } \\
\text { limitation }\end{array}$ & & & & \\
\hline \multirow[t]{5}{*}{ DE-CTA } & \multirow[t]{3}{*}{ artifacts } & none & 877 & 6 & 10 & 13 & 0 & 906 & 89.3 \\
\hline & & present without limitation & 70 & 0 & 6 & 1 & 0 & 77 & 7.6 \\
\hline & & present with limitation & 28 & 0 & 0 & 0 & 0 & 28 & 2.8 \\
\hline & \multicolumn{2}{|c|}{ not assessable } & 1 & 0 & 0 & 0 & 0 & 1 & 0.1 \\
\hline & \multicolumn{2}{|c|}{ not visualized } & 2 & 0 & 0 & 0 & 0 & 2 & 0.2 \\
\hline \multicolumn{3}{|l|}{ SUM } & 978 & 6 & 16 & 14 & 0 & 1014 & \\
\hline \multicolumn{3}{|l|}{ [\%] } & 96.4 & 0.6 & 1.6 & 1.4 & 0.0 & & \\
\hline
\end{tabular}

\section{Impact of calcifications, image quality, and image artifacts on the diagnostic performance of DE-CTA}

The impact of calcifications, image quality, and image artifacts on the sensitivity and specificity of DE-CTA was evaluated using Fisher's exact tests. The degree of calcification had a significant influence on both the sensitivity and specificity of DE-CTA. Fisher's Exact tests resulted in $p=0.005$ for DSA-positive and $p<0.001$ for DSA-negative segments (reader 1 ), and in $p<0.001$ for both DSA-positive and DSA-negative segments (reader 2). Reader 1 achieved a sensitivity of $91.1 \%$ for strongly calcified (grade 4 ) and $70.0 \%$ for minimally calcified arterial segments. The specificity decreased from $81.2 \%$ to $46.2 \%$ with an increasing degree of calcification.

The image quality did not significantly influence the sensitivity. However, the specificity significantly increased with a higher image quality from $70.0 \%$ to $76.4 \%$. Fisher's Exact tests resulted in $p=0.3287$ for DSA-positive and $p<0.001$ for DSA-negative segments (reader 1 ), and in $p<0.396$ for DSA-positive and $p=0.004$ for DSA-negative segments (reader 2).

Image artifacts, categorized as suboptimal enhancement, motion artifacts, venous contamination, beam-hardening, or other artifacts, did not significantly influence the sensitivity or specificity of reader 1 ( $\triangleright$ Table 5 ). However, artifacts that limited the image interpretation of reader 2 decreased his specificity. Fisher's Exact tests resulted in $p=0.807$ for DSA-positive and $p<0.623$ for DSA-negative segments (reader 1 ), and in $p<0.057$ for DSA-positive and $p<0.001$ for DSA-negative segments (reader 2 ). 


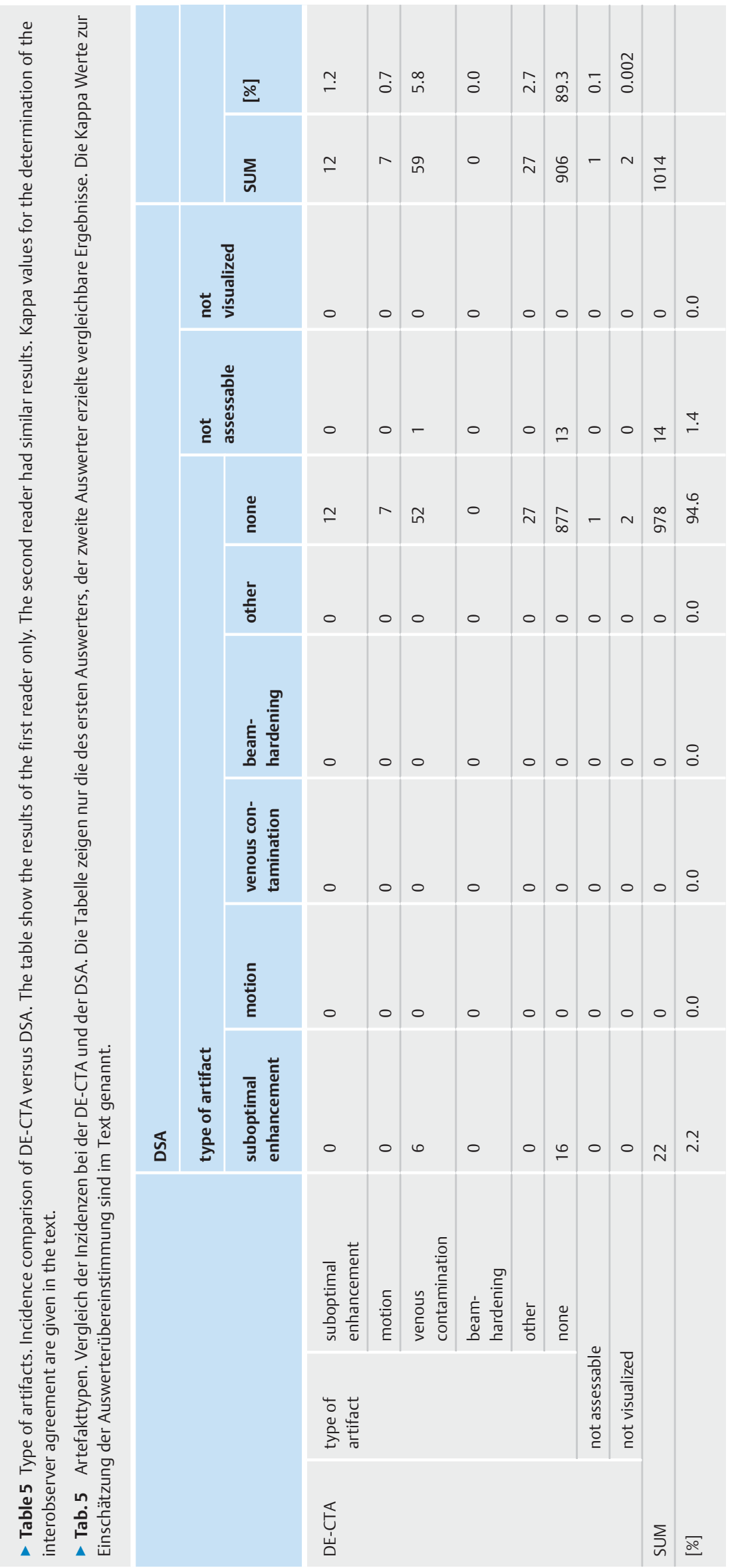


- Table 6 Diagnostic accuracy of DE-CTA in comparison to the diagnostic reference standard DSA. An extremity was considered disease-positive when it included at least one true-positive arterial segment.

- Tab. 6 Diagnostische Genauigkeit der DE-CTA im Vergleich zum diagnostischen Referenzstandard DSA. Bei der Auswertung pro Extremität wurde die Extremität dann als erkrankt angesehen, wenn diese mindestens ein „richtig-positives“ Segment aufwies.

\begin{tabular}{|l|c|c|c|c|c|c|}
\hline & TP & TN & FP & FN & $\begin{array}{l}\text { Sens } \\
\text { [\%] }\end{array}$ & $\begin{array}{l}\text { Spec } \\
{[\%]}\end{array}$ \\
\hline & & & & & & \\
\hline
\end{tabular}

Abbr.: R: reader; TP: true positive, TN: true negative, FP: false positive; FN: false negative; Sens: sensitivity; Spec: specificity; LR: likelihood ratio.

- Table 7 Diagnostic accuracy of DE-CTA grouped by arterial segment in comparison to the diagnostic reference standard DSA. Diagnostic accuracy decreases from proximal to distal. The arterial segment size and the vessel course orthogonal to the axial CTA image plane seem to have particular influence on diagnostic accuracy.

- Tab.7 Die diagnostische Genauigkeit der DE-CTA gruppiert nach arteriellen Segmenten im Vergleich zum diagnostischen Referenzstandard DSA. Die diagnostische Genauigkeit nimmt von proximal nach distal ab. Die Größe des arteriellen Segmentes und ein möglichst orthogonaler Verlauf zur axialen CTA Bildebene scheinen einen wesentlichen Einfluss auf die diagnostische Genauigkeit zu haben.

\begin{tabular}{|c|c|c|c|c|c|c|c|c|c|}
\hline \multirow[b]{2}{*}{ artery } & \multicolumn{4}{|c|}{ reader 1} & \multicolumn{4}{|c|}{ reader 2} & \multirow[b]{2}{*}{$\mathbf{K}$} \\
\hline & $\begin{array}{l}\text { Sens } \\
\text { [\%] }\end{array}$ & $\begin{array}{l}\text { Spec } \\
{[\%]}\end{array}$ & $\begin{array}{l}\text { Acc } \\
{[\%]}\end{array}$ & $\mathbf{n}$ & $\begin{array}{l}\text { Sens } \\
\text { [\%] }\end{array}$ & $\begin{array}{l}\text { Spec } \\
{[\%]}\end{array}$ & $\begin{array}{l}\text { Acc } \\
{[\%]}\end{array}$ & n & \\
\hline AA & 100 & 75 & 76 & 34 & 100 & 100 & 100 & 34 & 0.145 \\
\hline $\mathrm{ClA}$ & 71 & 81 & 78 & 41 & 79 & 92 & 88 & 40 & 0.64 \\
\hline IIA & 75 & 35 & 40 & 35 & 75 & 45 & 49 & 35 & 0.479 \\
\hline EIA & 70 & 90 & 85 & 39 & 90 & 83 & 85 & 39 & 0.584 \\
\hline CFA & 100 & 89 & 89 & 76 & 100 & 91 & 91 & 76 & 0.59 \\
\hline FAB & 100 & 94 & 94 & 85 & 100 & 92 & 92 & 85 & 0.451 \\
\hline SFA & 91 & 62 & 75 & 83 & 86 & 82 & 84 & 93 & 0.382 \\
\hline PFA & 40 & 83 & 80 & 86 & 40 & 88 & 85 & 87 & 0.659 \\
\hline PA & 100 & 55 & 65 & 82 & 94 & 63 & 70 & 82 & 0.552 \\
\hline TFT & 93 & 38 & 59 & 76 & 81 & 45 & 59 & 71 & 0.639 \\
\hline ATA & 86 & 50 & 74 & 73 & 36 & 82 & 60 & 69 & 0.708 \\
\hline PTA & 88 & 61 & 74 & 57 & 88 & 56 & 84 & 53 & 0.355 \\
\hline FA & 92 & 50 & 86 & 72 & 30 & 79 & 46 & 68 & 0.728 \\
\hline DPA & 69 & 43 & 60 & 60 & 30 & 79 & 46 & 56 & 0.365 \\
\hline PPA & 83 & 52 & 65 & 72 & 75 & 71 & 72 & 69 & 0.487 \\
\hline
\end{tabular}

Abbr.: Sens: sensitivity; Spec: specificity; Acc: accuracy; n: number of segments. 


\section{Discussion}

DE-CTA is helpful in the diagnosis of PAOD in comparison to the traditional diagnostic reference standard DSA. The two observers had sensitivities of $98.0 \%$ and $93.9 \%$ and specificities of $75.0 \%$ and $66.7 \%$ for detecting stenoses of $>50 \%$ of the lower extremity arteries.

Two other comparable studies have been published with smaller collectives, in which DE-CTA was evaluated in comparison to DSA $[12,13]$ : In the study of Brockmann et al., almost equivalent sensitivity of $97.2 \%$ was achieved. The reported specificity of $94.1 \%$ was higher than that of the readers of our study. Probable reasons for this difference may be the selection of a $70 \%$ stenosis level for relevant disease, and the exclusion of the pedal arteries from their analysis. Furthermore, our study includes significantly more patients at a progressed disease stage or critical limb ischemia. We included 79 ( $84 \%$ of $n=94$ ) patients with Fontaine stage 4 in comparison to 6 ( $30 \%$ of $n=20$ ) patients. In the study of Kau et al., the authors reported good sensitivity of $84 \%$ and moderate specificity of $67 \%$ for a cohort of 58 patients. They also included the pedal arteries, and, like us, described low diagnostic accuracy of DE-CTA for these arterial segments. Both studies primarily focused on maximum intensity projections (MIPs) for assessing arterial segments, whereas axial reconstructions and MIPs were used in the presented study. Several other studies of CTA in the diagnosis of PAOD have revealed good to excellent accuracy for mono-energetic acquisitions [6, 14 - 17]. Among these, extremely high sensitivities of $99 \%$ and specificities of $98 \%$ were reported in two studies. At first glance, these numbers obviously call into question the necessity for the dual-energy technique. In the first study on 41 patients with critical limb ischemia, pedal arteries were excluded from analysis. Furthermore, the methodology was not designed for assessing extremely calcified, inadequately opacified, or artifact-afflicted segments [18]. In the second study on 28 patients with a predominately intermediate disease stage, the methodology lacks precision regarding the inclusion of pedal arteries, the rejection of inappropriately visualized segments, as well as the independence and the interobserver agreement of the cardiologists interpreting the CTA images [17]. Overall, we had higher diagnostic accuracy for proximal than for distal arterial segments, but observed an accuracy drop for the IIA. This may be explained by a more tortuous vessel course.

DE-CTA overestimated the number of relevant artery stenoses in comparison to DSA ( $\triangleright$ Table 1, $\triangleright$ Fig. 3 ). DSA excluded relevant disease in 652 (64.2\%) arterial segments, DE-CTA in only 499 (49.2\%). The number of occlusions was comparable (DSA, 232, DE-CTA, 213). These observations can be explained by the significant impact of calcifications on stenosis degree interpretation. We observed a decrease in specificity in highly calcified segments. In these segments the sensitivity increased potentially due to the higher probability and incidence of positive findings. Furthermore, DE-CTA displayed more and stronger calcifications than DSA. Calcifications were excluded in 761 (75\%) of arterial segments by DSA and in 371 (36\%) segments by DE-CTA. In contrast, severe calcifications were detected in 407 (40.1\%) segments by DE-CTA and in $18(1.8 \%)$ segments by DSA. At the lower extremities, it is well known that CTA renders direct and sensitive depiction of calcified plaques around the vascular circumference.
This results in higher precision for plaque assessment than DSA and renders plaque characterization and composition analysis. However, calcified plaques can impair the evaluation of the vascular lumen and precise stenosis grading. In strongly calcified arteries or in atherosclerotic segments below the knee, CTA reporting thus requires more intensive and time-consuming image postprocessing and evaluation. As calcifications also had a strong impact on the accuracy of DE-CTA, the resulting decrease in specificity may lead to a number of patients undergoing invasive DSA for therapeutic reasons without having relevant stenosis.

The image quality of DE-CTA was good in $63.5 \%$ of images and excellent in $30.6 \%$. DSA images were considered to have excellent quality in $96 \%$ of cases, probably due to potential repetitions of DSA acquisitions. Impaired quality of DE-CTA images significantly reduced the specificity. Images were free of artifacts in $96.4 \%$ of DSA and $89.3 \%$ of DE-CTA acquisitions. The $7.7 \%$ more artifacts on DE-CTA images were due to suboptimal enhancement, motion or venous contamination. Surprisingly, artifacts did not necessarily lead to limitations of image interpretation. While most artifacts may be avoided using DSA by just repeating the acquisition and only sending the optimal image to the PACS, DE-CTA is normally performed without repetitions in order to limit radiation exposure and the amount of applied contrast material. Suboptimal contrast enhancement or venous contamination is mostly unavoidable using DE-CTA when non-time-resolved acquisitions are performed. Several studies have given recommendations for optimal contrast material concentration, amount, and injection rate as well as CT acquisition parameters that lead to improved, artifactdeprived image quality [19, 20]. In our study, rather low volumes of contrast agent were applied in a fixed protocol in comparison to other studies [12, 21]. The DE-CTA technique allows for reduced contrast material concentrations utilizing the abundant photoelectric effect at lower tube voltages [22]. Thus, the DE-CTA technique may be performed with a lower risk of contrast material-induced nephropathy. The reduction of this risk is important, as advanced PAOD is frequently found in patients with diabetes mellitus and concomitant nephropathy.

In our study, patients were scanned using a dual-source dualenergy CT machine from the first generation. Recently, a thirdgeneration scanner was introduced. The technical developments include improved $\mathrm{X}$-ray detectors providing higher resolution and better image quality due to reduced electronic noise [23]. Furthermore, iterative reconstruction algorithms have been incorporated by most vendors that increasingly replace the filtered backprojection algorithms as they allow for reduced radiation doses and higher image quality due to a reduction of image noise [24]. However, the impact of iterative reconstruction on CTA of the lower extremities requires evaluation as it has been shown that the quantification of calcified coronary artery plaques may be impaired with increasing iteration levels [25].

Our study was limited by its retrospective design. Differences in diagnostic accuracy in comparison to other studies may result from a selection bias. DE-CTA scans had not been performed for study purposes, but in the clinical routine and may have resulted in predominantly high disease stages of PAOD or critical limb ischemia. Furthermore, accompanying diseases such as diabetes mellitus or renal insufficiency as well as specific demographics 

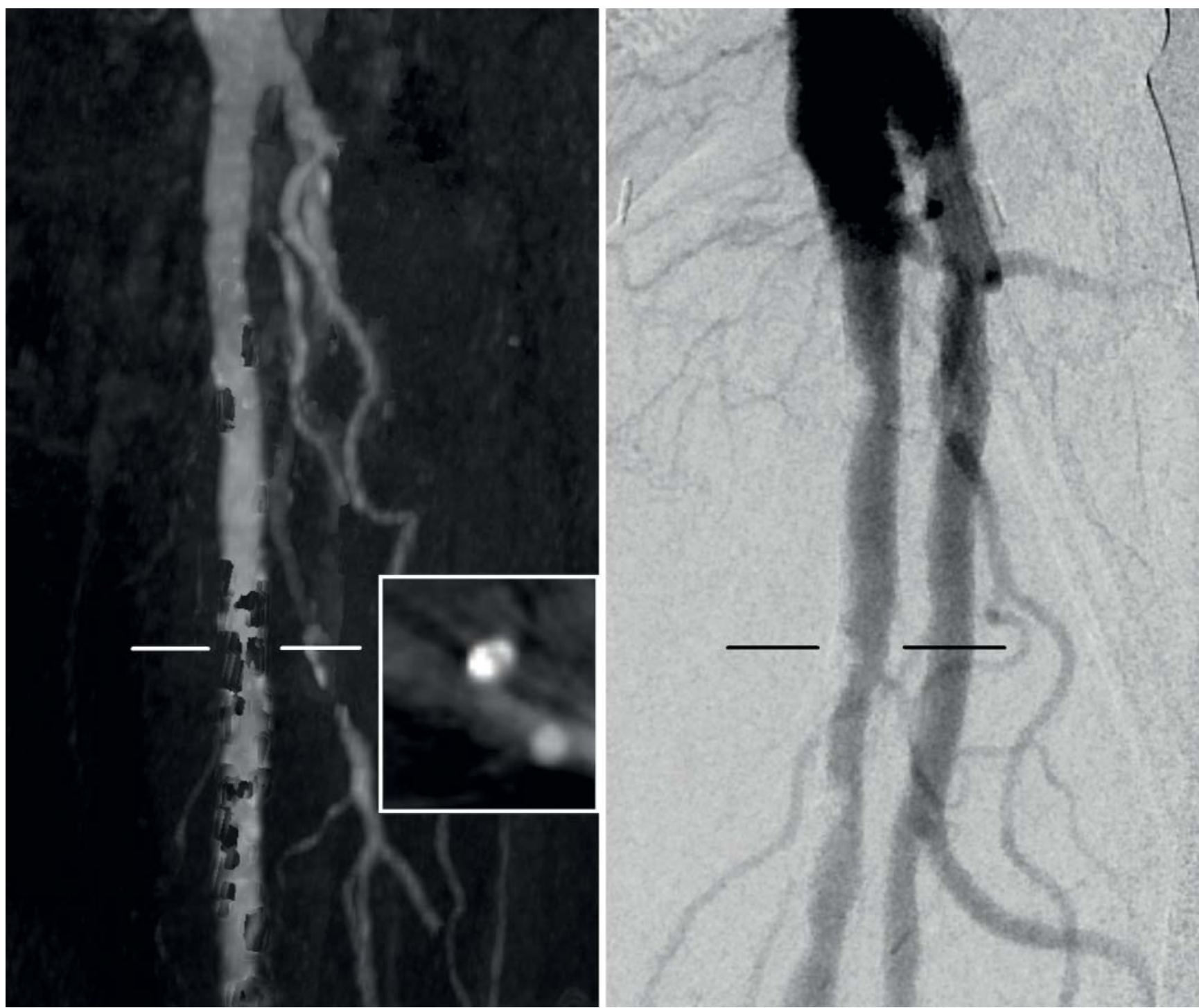

- Fig. 3 The stenosis degree can be overestimated on coronal MIP images with bone and plaque removal (left image) as well as on axial combined DE images (extract within the left image) in comparison to the reference standard DSA (right images). In this patient, DE-CTA images led to the assumption of a high-grade stenosis of the proximal superficial femoral artery, whereas the DSA image demonstrates lumen narrowing of $<50 \%$.

- Abb. 3 Der Stenosegrad kann auf koronaren MIP Bildern mit Knochen- und Plaqueentfernung (linkes Bild) sowie auf axialen, kombinierten DEBildern (Ausschnitt im linken Bild) im Vergleich zur DSA überschätzt werden. Bei diesem Patienten wurde anhand der DE-CTA Bilder eine hochgradige Stenose der proximalen A. femoralis superficialis vermutet, während die DSA eine Lumeneinengung von $<50 \%$ zeigte.

could not have been previously selected. All patients have had high treatment probability; otherwise the invasive DSA procedure would not have been indicated. None of our patients had been examined for only diagnostic purposes. DSA series had been acquired for the diseased extremity only, usually not for both sides. The retrospective study design did not allow control of the vascular access technique, which had been individually chosen using an antegrade direct or retrograde cross-over puncture technique. This resulted in a lower number of matching aorta and pelvis segments on DE-CTA and DSA images. A selection bias may also have occurred, when excluding arterial segments from evaluation due to e. g. image artifacts. The total contrast material volume was $80 \mathrm{ml}$ for DECTA studies, and 80 - $90 \mathrm{ml}$ for DSA studies. However, we have not documented the individual volume for each DSA study. The methodology was partly based on subjective evaluation criteria. This may have resulted in limited precision of measurements and variability in grading scales, but reflects realworld conditions and allows for the assessment of interobserver agreement in clinical routine processes. The number of observers, two independent CTA readers and one DSA reader, may have resulted in a further bias. Finally, we considered a lumen reduction of $>50 \%$, which is a frequently used cut-off value in the literature, to be a stenosis-positive finding [5]. One may consider stenoses of $>70 \%$ clinically relevant, whereas the true hemodynamic relevance can be assessed by measuring pressure gradients. The yield of DECTA may have been overestimated and may have resulted in concordance of both readers, as we assessed stenotic lesions per segment and region, but not each particular lesion. DSA may have 
displayed more findings than DE-CTA, when unperceived embolic events have occurred during the period between the two studies. Finally, we haven't documented or evaluated radiation doses for study purposes of the DE-CTA scans. Patients were scanned with DE tube voltage settings of 140 and $80 \mathrm{kVp}$ and effectively exposed to 50 and $270 \mathrm{mAs}$, respectively. These acquisition parameters were comparable to that of other studies, e. $\mathrm{g}$. DE-CTA studies with the identically constructed CT machine exposing $56 \mathrm{mAs}$ at $140 \mathrm{kVp}$ and $238 \mathrm{mAs}$ at $80 \mathrm{kVp}$ resulted in a mean CTDIvol of $4.1 \mathrm{mGy}$ (range: $2.8-6.2 \mathrm{mGy}$ ) [21]. The scan time of the CTA studies was not documented, as we did not consider this parameter relevant for our conclusions.

\section{Conclusion}

DE-CTA is accurate in the detection of lower extremity artery stenoses of $>50 \%$ in symptomatic POAD patients. Atherosclerotic calcifications, image quality, and artifacts did not significantly influence the sensitivity of DE-CT, but atherosclerotic calcifications significantly reduced and artifacts partly reduced the specificity of DE-CTA. The overall interobserver agreement ranged between moderate and substantial for stenosis detection and calcified plaque assessment.

\section{CLINICAL RELEVANCE OF THIS STUDY}

- The diagnostic accuracy of DE-CTA plays a key role for justifying its implementation as a noninvasive, pre-interventional imaging modality in the diagnostic workup of patients with critical limb ischemia or severe disease stage.

- Difficulties or limitations in the interpretability of CTA images often experienced in patients with progressed POAD and severe calcifications may be facilitated using dual-energy CTA acquisitions.

- Despite the benefits of bone and plaque removal on DE-CTA images, diagnostic specificity can be impeded by atherosclerotic calcifications and imaging artifacts.

\section{Conflict of Interest}

No conflict of interest has been declared by the author(s).

References

[1] Huppert P, Tacke J, Lawall H. S3 guidelines for diagnostics and treatment of peripheral arterial occlusive disease. Radiologe 2010; 50: 7-15

[2] Norgren L, Hiatt WR, Dormandy JA et al. Inter-society consensus for the management of peripheral arterial disease. Int Angiol 2007; 26: 81 - 157

[3] Ortiz D, Jahangir A, Singh M et al. Access Site Complications After Peripheral Vascular Interventions Incidence, Predictors, and Outcomes. Circ Cardiovasc Interv 2014; 7: 821 - 828

[4] Napoli A, Anzidei M, Zaccagna F et al. Peripheral Arterial Occlusive Disease: Diagnostic Performance and Effect on Therapeutic Management of 64-Section CT Angiography. Radiology 2011; 261: 976-986

[5] Heijenbrok-Kal MH, Kock MCJM, Hunink MGM. Lower extremity arterial disease: multidetector CT angiography meta-analysis. Radiology 2007; 245: $433-439$
[6] Met R, Bipat S, Legemate DA et al. Diagnostic Performance of Computed Tomography Angiography in Peripheral Arterial Disease: A Systematic Review and Meta-analysis. JAMA: the Journal of the American Medical Association 2009; 301: 415-424

[7] Meyer BC, Werncke T, Foert E et al. Do the cardiovascular risk profile and the degree of arterial wall calcification influence the performance of MDCT angiography of lower extremity arteries? Eur Radiol 2010; 20: 497-505

[8] Johnson TRC, Krauss B, Sedlmair M et al. Material differentiation by dual energy CT: initial experience. Eur Radiol 2007; 17: 1510-1517

[9] Henzler T, Gruettner J, Meyer M et al. Coronary computed tomography and triple rule out $\mathrm{CT}$ in patients with acute chest pain and an intermediate cardiac risk for acute coronary syndrome: Part 2: Economic aspects. European Journal of Radiology 2013; 82: 106-111

[10] Fontaine R, Kim M, Kieny R. Surgical treatment of peripheral circulation disorders. Helv Chir Acta 1954; 21: 499-533

[11] Landis JR, Koch GG. The measurement of observer agreement for categorical data. Biometrics 1977; 33: 159-174

[12] Brockmann C, Jochum S, Sadick M et al. Dual-energy CT angiography in peripheral arterial occlusive disease. Cardiovasc Intervent Radiol 2009; 32: $630-637$

[13] Kau T, Eicher W, Reiterer $C$ et al. Dual-energy $C T$ angiography in peripheral arterial occlusive disease-accuracy of maximum intensity projections in clinical routine and subgroup analysis. Eur Radiol 2011; 21: 1677-1686

[14] Miller JM, Rochitte CE, Dewey M et al. Diagnostic Performance of Coronary Angiography by 64-Row CT. N Engl J Med 2008; 359: 2324-2336

[15] Duan Y, Wang X, Yang X et al. Diagnostic Efficiency of Low-Dose CT Angiography Compared With Conventional Angiography in Peripheral Arterial Occlusions. Am J Roentgenol 2013; 201: W906-W914

[16] Sun Z. Diagnostic Accuracy of Multislice CT Angiography in Peripheral Arterial Disease. Journal of Vascular and Interventional Radiology 2006; 17: $1915-1921$

[17] Shareghi S, Gopal A, Gul K et al. Diagnostic Accuracy of 64 Multidetector Computed Tomographic Angiography in Peripheral Vascular Disease. Catheter Cardiovasc Interv 2010; 75: 23-31

[18] Fotiadis N, Kyriakides C, Bent C et al. 64-section CT angiography in patients with critical limb ischaemia and severe claudication: Comparison with digital subtractive angiography. Clin Radiol 2011; 66: 945-952

[19] Baxa J, Vendiš T, Moláček J et al. Low contrast volume run-off CT angiography with optimized scan time based on double-level test bolus technique feasibility study. European Journal of Radiology 2014; 83: e147-e155

[20] Meyer BC, Oldenburg A, Frericks BB et al. Quantitative and qualitative evaluation of the influence of different table feeds on visualization of peripheral arteries in $\mathrm{CT}$ angiography of aortoiliac and lower extremity arteries. Eur Radiol 2008; 18: 1546-1555

[21] Meyer BC, Werncke T, Hopfenmüller W et al. Dual energy CT of peripheral arteries: Effect of automatic bone and plaque removal on image quality and grading of stenoses. European Journal of Radiology 2008; 68: $414-422$

[22] Almutairi A, Sun Z, Poovathumkadavi A et al. Dual Energy CT Angiography of Peripheral Arterial Disease: Feasibility of Using Lower Contrast Medium Volume. PLoS ONE 2015; 10: e0139275

[23] Solomon J, Wilson J, Samei E. Characteristic image quality of a third generation dual-source MDCT scanner: Noise, resolution, and detectability. Medical Physics 2015; 42: 4941-4953

[24] Klink T, Obmann V, Heverhagen J et al. Reducing CT radiation dose with iterative reconstruction algorithms: the influence of scan and reconstruction parameters on image quality and CTDIvol. European Journal of Radiology 2014; 83: 1645 - 1654

[25] Obmann VC, Klink T, Heverhagen JT et al. Impact of Hybrid Iterative Reconstruction on Agatston Coronary Artery Calcium Scores in Comparison to Filtered Back Projection in Native Cardiac CT. Fortschr Röntgenstr 2015; 187: 372-379 